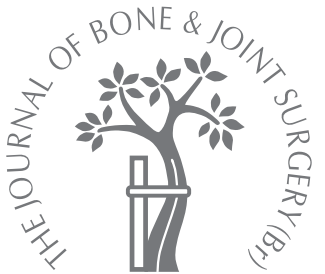

J. Scott

Editor,

the Journal of Bone and Joint Surgery

- EDITORIAL

\title{
Frank Horan Essay Prize
}

One of the particular characteristics which Sir Reginald Watson-Jones brought to editing and writing was clarity. He brought this spectacularly to his textbook Fractures and Joint Injuries which was first published in 1940. In an introduction to the sixth edition in 1982 Philip Newman described the text as being "so masterfully and appealingly compiled". He also, of course, brought this writing style to our Journal, of which he was the first Editor in 1948 and successive Editors have attempted to continue the tradition. None has done so as successfully as Frank Horan. He has worked for the Journal for more than 30 years, during which time we estimate that he has edited more than 2000 papers as well as writing countless chapters in textbooks and other material. Now in his mid-70's, he continues to edit quickly and concisely and also to travel extensively representing the Journal and speaking on how to write papers, most recently in India, Greece and China.

In order to mark this vast experience we are establishing an essay prize in his honour. The Frank Horan Essay Prize will be open to all orthopaedic trainees worldwide. It will be awarded annually and submissions will be invited later in the year through the website. The submissions can be on any aspect of clinical orthopaedics, and should be limited to 3000 words, containing no more than 30 references and 5 figures. The winning submission will be published in the Journal and there will be a small accompanying financial reward. Particular favour will of course be given to “masterful and appealing” submissions.
J. Scott, MA, FRCS, Editor Journal of Bone and Joint Surgery, 22 Buckingham Street, London WC2N 6ET, UK.

Correspondence should be sent to $\mathrm{Mr}$ J. Scott; e-mail: j.scott@jbjs.org.uk

(C)2009 British Editorial Society of Bone and Joint Surgery doi:10.1302/0301-620X.91B4 $22433 \$ 2.00$

$J$ Bone Joint Surg $[\mathrm{Br}]$ 2009:91-B:425.

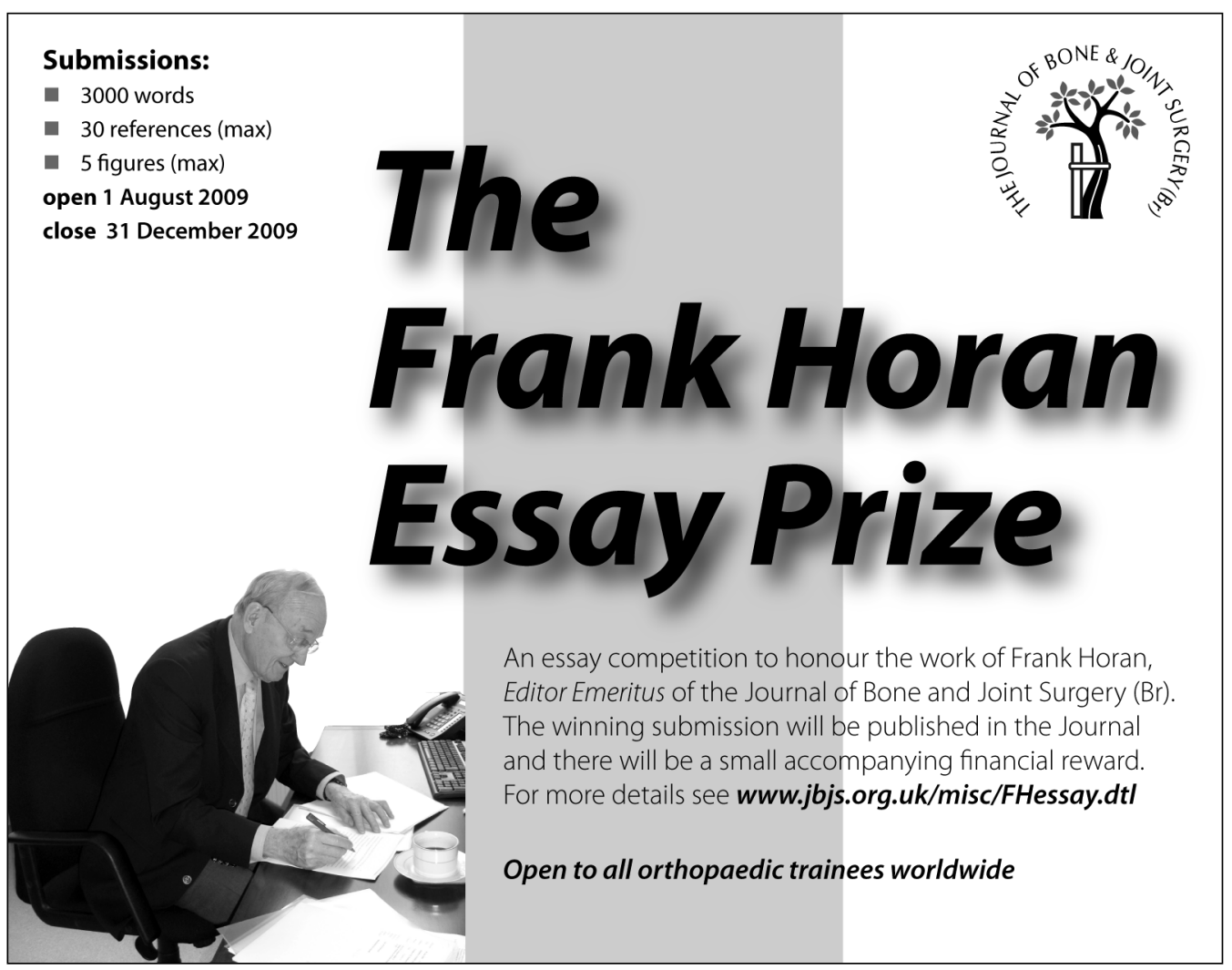

